\title{
The heat shock protein 90 inhibitor SNX-2112 inhibits B16 melanoma cell growth in vitro and in vivo
}

\author{
KAI-SHENG LIU ${ }^{1,2^{*}}$, WEI-CHAO DING ${ }^{1 *}$, SHAO-XIANG WANG $^{1}$, ZHONG LIU $^{1}$, \\ GUO-WEN XING ${ }^{4}$, YING WANG ${ }^{3}$ and YI-FEI WANG ${ }^{1}$ \\ ${ }^{1}$ Guangzhoujinan Biomedicine Research and Development Center, Guangdong Provincial Key Laboratory of \\ Bioengineering Medicine, National Engineering Research Center of Genetic Medicine, ${ }^{2}$ Pharmacy College \\ and ${ }^{3}$ College of Life Science and Technology, Jinan University, Guangzhou 510632; \\ ${ }^{4}$ Chemistry College, Beijing Normal University, Beijing 100875, P.R. China
}

Received January 5, 2012; Accepted February 12, 2012

DOI: $10.3892 /$ or.2012.1738

\begin{abstract}
SNX-2112 is a selective heat shock protein 90 (Hsp90) inhibitor which can exert a potent anticancer activity. In this study, we investigated the effects of SNX-2112 on B16 melanoma cells in vitro and in vivo. The 3-(4,5-dimetrylthiazol2-yl)-2, 5-diphenyltetrazolium bromide (MTT) assay and flow cytometric analysis demonstrated that SNX-2112 dosedependently inhibited the growth of B16 cells, and induced G0/ G1 cell cycle arrest and apoptosis. Western blotting revealed that SNX-2112 lead to the degradation of Hsp90 client proteins including Akt, IKK $\alpha$, NF- $\mathrm{kB}$, B-Raf and GSK3 $\beta$. Furthermore, we assessed the antitumor effect of SNX-2112 in vivo, using a xenograft model in C57BL/6 mice. Oral administration of SNX-2112 significantly inhibited the growth of B16 tumors in mice, with a $47 \%$ inhibition observed at dose of $80 \mathrm{mg} / \mathrm{kg} / \mathrm{day}$ for 15 days, compared to control tumors. Hematoxylin-eosin (H\&E) staining of xenograft tissues showed that SNX-2112 also inhibited angiogenesis and lead to a lower blood vessel density in the tumors, compared to the control group. These findings demonstrate that SNX-2112 can exhibit a potent anticancer activity against B16 melanoma cells both in vitro and in vivo, by inhibiting cell proliferation and inducing cell cycle arrest and apoptosis in a mechanism dependent on the degradation of Hsp90 client proteins.
\end{abstract}

Correspondence to: Dr Yi-Fei Wang, Guangzhoujinan Biomedicine Research and Development Center, Jinan University, Guangzhou 510632, P.R. China

E-mail: twang-yf@163.com

Dr Ying Wang, College of Life Science and Technology, Jinan University, Guangzhou 510632, P.R. China

E-mail: yingwang331@163.com

${ }^{*}$ Contributed equally

Key words: heat shock protein 90 inhibitor, SNX-2112, apoptosis, client protein, B16 cells, tumor growth

\section{Introduction}

Hsp90 is an important ATP-dependent molecular chaperone required for protein folding, as well as the assembly and maintenance of the conformational stability of a diverse range of client proteins. Hsp90 client proteins play key roles in cellular metabolism, trafficking, signal transduction, chromatin remodeling, cell growth and differentiation (1-4). Hsp90 client proteins include cell survival and proliferation regulators, such as Akt, IKK, Raf, GSK3 and NF-kB (5-7). Hsp90 is overexpressed in tumor cells compared to their normal counterparts (8), and inhibition of Hsp90 has been considered as a possible strategy for the treatment of cancer.

Currently, 14 drug candidates which target Hsp90 are undergoing clinical trials for multiple indications, either as single agents or in combination therapy, including 17-(allylamino)-17-demethoxygeldanamycin (17-AAG), 17-allylamino-17-demethoxygeldanamycin hydroquinone hydrochloride (IPI-504) and BIIB021 (9). 17-AAG was the first Hsp90 inhibitor to undergo phase III clinical trials, and is well tolerated and has a good therapeutic efficacy. However, 17-AAG has several potential limitations, including poor solubility, limited bioavailability and unsatisfactory hepatotoxicity (10-12). This has led to efforts to identify new, safer and more effective Hsp90 inhibitors for clinical applications.

SNX-2112, a selective Hsp90 inhibitor, can bind to the $\mathrm{N}$-terminal adenosine triphosphate binding site of Hsp90 and can exert significant growth inhibition of various cancer cell lines both in vitro and in vivo $(13,14)$. In our previous research, SNX-2112 displayed promising anti-tumor activity in human chronic leukemia K562 cells and MCF-7 cells $(15,16)$. In addition, SNX-2112 is a more effective agent than 17-AAG. For example, SNX-2112 can induce cell growth inhibition and cell cycle arrest, and cause apoptosis in a more potent dose-dependent manner than 17-AAG (16). However, the molecular mechanisms by which Hsp90 inhibitors exert an anticancer effect require further elaboration. In this study, we investigated the effect of SNX-2112 on B16 cells in vitro and in vivo. We investigated the effect of SNX-2112 on cell proliferation, the cell cycle, apoptosis and the expression of Hsp90 client proteins in B16 cells in vitro. Additionally, we investigated the effect of SNX-2112 on tumor 
growth and blood vessel density in vivo, using a mouse xenograft model.

\section{Materials and methods}

Reagents and cells. SNX-2112 was synthesized in our laboratory as previously described (17). Dimethylsulfoxide (DMSO), 4',6-diamidino-2-phenylindole (DAPI), and MTT were purchased from Sigma (St. Louis, MO, USA). Antibodies against GAPDH and Akt were purchased from Cell Signaling Technology (Beverly, MA, USA), antibodies against IKK $\alpha$ and GSK3 $\beta$ were purchased from Epitomics (Burlingame, CA, USA) and antibodies against NF- $\kappa \mathrm{B}$ and B-Raf were obtained from Santa Cruz Biotechnology (Santa Cruz, CA, USA).

The B16 cell line was obtained from the Cell Bank of Chinese Science Academy (Shanghai, China) and cultured in RPMI-1640 medium containing $10 \%$ fetal bovine serum (FBS) and $1 \%$ streptomycin and penicillin in a $5 \% \mathrm{CO}_{2}$ humidified incubator at $37^{\circ} \mathrm{C}$. Log-phase growth cells were used for all experiments.

MTT assay. B16 cells $\left(5 \times 10^{3}\right.$ cells/well) were seeded into a 96-well plate with various concentrations of SNX-2112 for 24 , 48 or $72 \mathrm{~h}$, then $20 \mu \mathrm{l} /$ well MTT solution $(5 \mathrm{mg} / \mathrm{ml})$ was added, the plates were incubated for an additional $4 \mathrm{~h}$, the supernatants were removed, and the formazan crystals were solubilized in $100 \mu \mathrm{l} /$ well DMSO and cell viability was assessed at an optical density of $570 \mathrm{~nm}$. All samples were tested in triplicate.

DAPI staining assay. B16 cells $\left(6 \times 10^{4}\right.$ cells $\left./ \mathrm{ml}\right)$ were seeded into chamber dishes and treated with $0.2 \mu \mathrm{M} \mathrm{SNX}-2112$ for $48 \mathrm{~h}$. The cells were twice washed in ice-cold PBS, fixed in $4 \%$ paraformaldehyde for $15 \mathrm{~min}$ at room temperature, washed with ice-cold PBS, stained with $5 \mu \mathrm{g} / \mathrm{ml}$ DAPI for $10-15 \mathrm{~min}$, and then examined by fluorescence microscopy. Apoptotic cells were identified by chromatin condensation and fragmentation.

Cell cycle distribution analysis. Cell cycle distribution was determined by staining the DNA with propidium iodide (PI). Briefly, B16 cells were cultured and treated in 6-well plates with

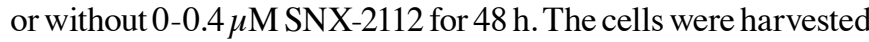
in cold PBS, fixed in 70\% ethanol overnight, collected, resuspended in PBS containing $50 \mu \mathrm{g} / \mathrm{ml} \mathrm{PI}$ and $0.1 \mathrm{mg} / \mathrm{ml}$ RNase and incubated at $37^{\circ} \mathrm{C}$ for $30 \mathrm{~min}$. The cells were analyzed on a flow cytometer (Becton-Dickinson, San Jose, CA, USA).

Quantification of apoptosis. Apoptosis was measured by flow cytometry using Annexin V-FITC (an apoptotic cell marker) and PI (necrotic cell marker) staining. The staining was performed according to protocol of the Annexin-V-FITC/PI staining kit (BioVision, Mountain View, CA, USA). Briefly, B16 cells were cultured in the presence or absence of the indicated compounds for $48 \mathrm{~h}$, harvested, washed twice and resuspended in $500 \mu \mathrm{l} \mathrm{PBS}$ containing Annexin-V-FITC and PI. Apoptosis was determined as the percentage of Annexin-V-FITC ${ }^{+}$and $\mathrm{PI}^{+}$cells in at least $1 \times 10^{4}$ cells from each sample.

Western blotting. The cells were washed twice in ice-cold PBS, lysed in RIPA buffer for $30 \mathrm{~min}$ on ice, centrifuged at 12,000 g for $15 \mathrm{~min}$ and the supernatants were collected. Equivalent amounts of lysate (20-30 $\mu \mathrm{g}$ ) were denatured in SDS sample buffer, resolved on 6-15\% SDS-PAGE gels, transferred to Immobilon-polyvinyldifluoride (PVDF) membranes, blocked in 5\% skimmed milk in Tris-buffered saline (TBS) containing $0.1 \%$ Tween-20 (TBST) at room temperature for $1 \mathrm{~h}$ and then probed with appropriate dilutions (1:100 to 1:5,000) of primary antibody overnight at $4^{\circ} \mathrm{C}$. The membranes were washed three times in TBST for $10 \mathrm{~min}$, incubated with secondary antibody $(1: 3,000)$ in TBST at room temperature for $1 \mathrm{~h}$, washed and the bound antibodies were detected using BeyoECL Plus (Beyotime, Haimen, China) following the manufacturer's instructions. AntiGAPDH antibodies were used as loading controls.

Xenograft murine model. Specific pathogen-free (SPF) C57BL/6 mice (16 g) were obtained from the Medical Laboratory Animal Center of Guangdong Province, China, housed at $20 \pm 2^{\circ} \mathrm{C}$ and $55 \pm 5 \%$ relative humidity and provided with commercial food and water ad libitum through the experiment. All studies were performed in compliance with the Institutional Animal Care Guidelines. The mice were inoculated with $2 \times 10^{6} \mathrm{~B} 16$ cells in the armpit. When the tumors were measurable, the mice were randomly assigned into three treatment groups receiving oral SNX-2112 (20, 40 or $80 \mathrm{mg} / \mathrm{kg}$, daily for a total of 15 days) or the control group receiving oral vehicle alone (10\% DMSO), with a total oral dose of $200 \mu \mathrm{l} / 10 \mathrm{~g}$. All mice were euthanized at day 15 , and the tumors were excised and weighed to evaluate tumor growth inhibition. The effect of SNX-2112 on angiogenesis was evaluated by $H \& E$ staining of the tumor tissues.

Statistical analysis. All the data are the mean \pm SD of three independent experiments. Statistical analysis was performed using SPSS 13.0 for Windows (SPSS, Chicago, IL, USA). Differences between two groups were analyzed using the two-tailed Student's t-test and groups of three or more were analyzed using one-way ANOVA with multiple comparisons; ${ }^{*} \mathrm{P}<0.05$ and ${ }^{* *} \mathrm{P}<0.01$ were considered statistically significant.

\section{Results}

SNX-2112 is a more potent inhibitor of B16 cell growth than 17-AAG. We used the MTT assay to investigate the anti-tumor activity of SNX-2112 and 17-AAG in B16 melanoma cells. The cells were cultured in the presence of a range of concentrations of SNX-2112 or 17-AAG for 24, 48 or 72 h. As shown in Fig. 1, SNX-2112 significantly inhibited the proliferation of B16 cells in a dose- and time-dependent manner. B16 cells were much more sensitive to SNX-2112 than 17-AAG, with half-maximal inhibitory concentrations of 0.18 and $9.37 \mu \mathrm{M}$ at $48 \mathrm{~h}$, respectively. These data suggest that SNX-2112 has a significantly higher in vitro growth inhibitory effect in B16 cells than 17-AAG.

SNX-2112 induces G0/G1 cell cycle arrest in B16 cells. To probe the mechanism by which SNX-2112 inhibited cell growth, we incubated B16 cells with SNX-2112 $(0,0.1,0.2$ or $0.4 \mu \mathrm{M})$ for $48 \mathrm{~h}$, stained the cells with PI and determined the cell cycle distribution using flow cytometry. As shown in Fig. 2, SNX-2112 induced G0/G1 cell cycle arrest in a dose-dependent manner, in a similar manner to the growth inhibitory effect. After $48 \mathrm{~h}$, the relative percentages of G0/G1 phase cells in the control, $0.1,0.2$ and $0.4 \mu \mathrm{M}$ SNX-2112-treated groups were 56.5, 76.1, 78.4 and $79.7 \%$, respectively. The percentage of G0/G1 phase cells in the 
A

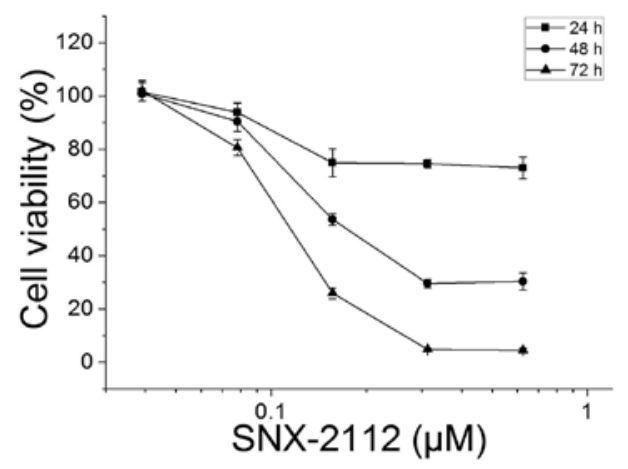

B

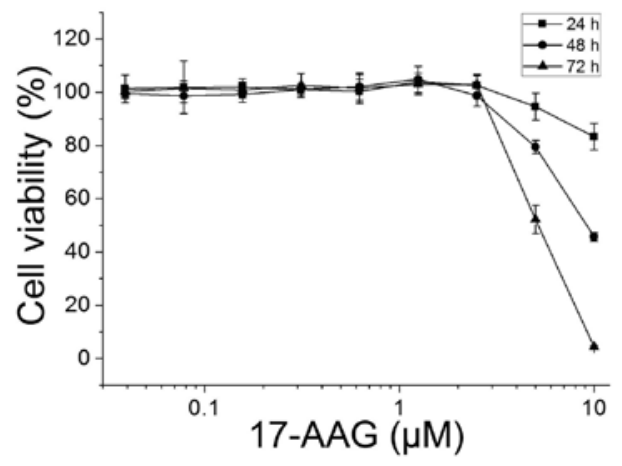

Figure 1. SNX-2112 and 17-AAG inhibit the growth of B16 cells. B16 cells were treated with different concentrations of SNX-2112 (A) or 17-AAG (B) for 24,48 and $72 \mathrm{~h}$, and the number of viable cells was determined using the MTT assay. All values are mean \pm SD of three independent experiments.
SNX-2112-treated groups were significantly higher than the control cells $(\mathrm{P}<0.01)$. The dose-dependent increase observed in the G0/G1-phase cell population of SNX-2112-treated cells was accompanied by a concomitant decrease in the $\mathrm{S}$ phase cell population. These results indicate SNX-2112 exerts a growth inhibitory effect in B16 cells by inducing cell cycle arrest at the G0/G1 checkpoint.

SNX-2112 induces apoptosis in B16 cells. DAPI staining was performed to determine if SNX-2112 induced morphological changes in the cell nucleus associated with apoptosis. DAPI staining indicated that the majority of chromatin in control cells had a normal, homogeneous distribution, whereas chromatin condensation and marginalization and/or DNA fragmentation was frequently observed in cells treated with SNX-2112 for $48 \mathrm{~h}$ (Fig. 3A). On the basis of the cell cycle analysis results, the presence of DNA condensation and the formation of apoptotic bodies indicated that SNX-2112 induced death in B16 cells via typical apoptotic cell death.

To further investigate whether the growth inhibitory effects of SNX-2112 were due to apoptosis, B16 cells were treated with SNX-2112 for 48 h, stained with Annexin V-FITC and PI and analyzed by flow cytometry. Fig. 3B shows that the percentage of necrotic and apoptotic cells (Annexin $\mathrm{V}^{+} / \mathrm{PI}^{+}$and Annexin $\mathrm{V}^{+} /$ $\mathrm{PI}^{-}$fraction) in control, 0.1, 0.2 and $0.4 \mu \mathrm{M} \mathrm{SNX}$-2112-treated cells were $3.96,31.52,62.84$ and $71 \%$, respectively. The number of necrotic and apoptotic cells in the SNX-2112-treated groups were significantly higher than control cells $(\mathrm{P}<0.01)$.
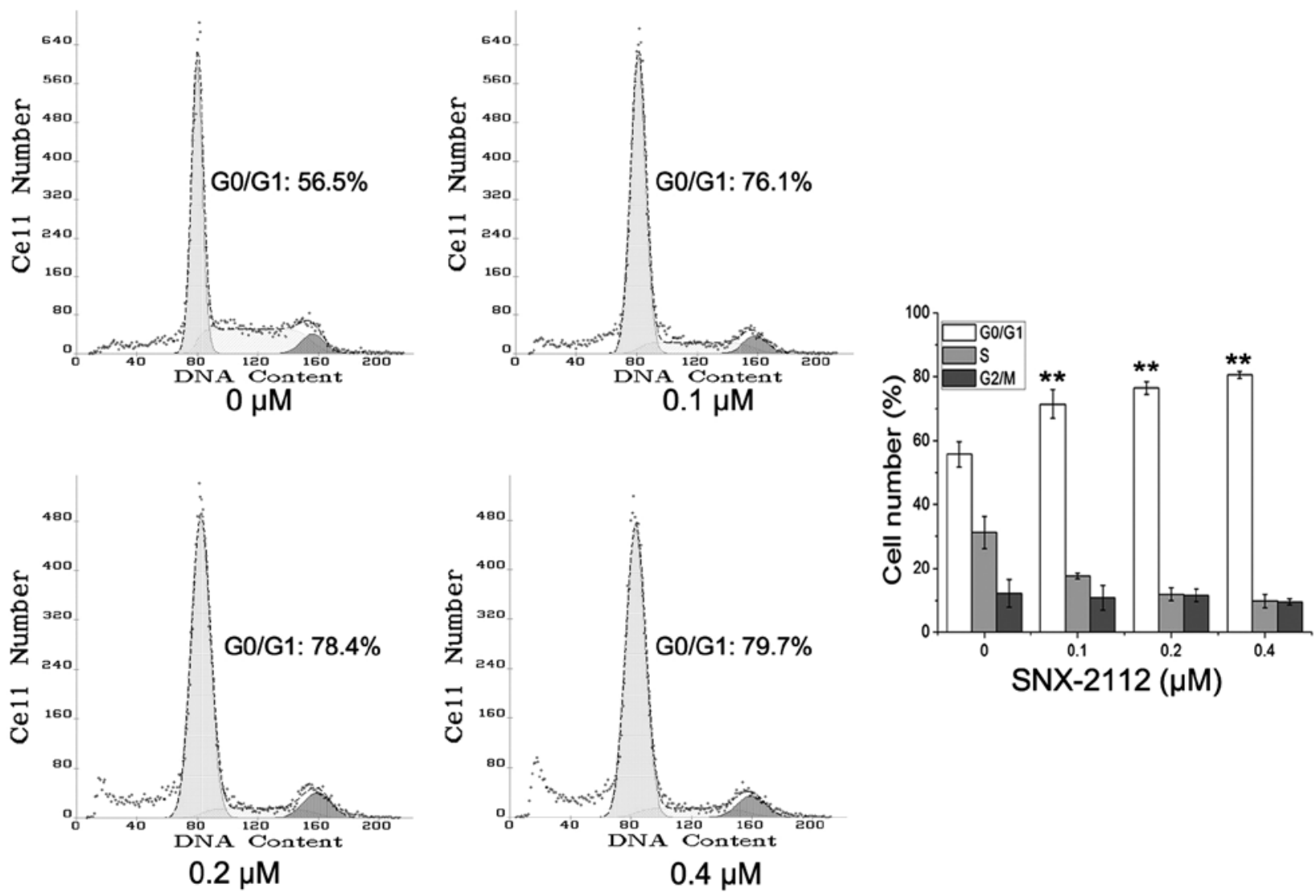

Figure 2. SNX-2112 induces G0/G1 cell cycle arrest in B16 melanoma cells. B16 cells were cultured with SNX-2112 at the indicated concentrations for 48 h. The nuclei were isolated, stained with propidium iodide (PI), and cell cycle distribution was determined by flow cytometry. All values are the mean \pm SD of three independent experiments with three replicates each; ${ }^{*} \mathrm{P}<0.05$ and ${ }^{* * *} \mathrm{P}<0.01$, compared to untreated control cells. 

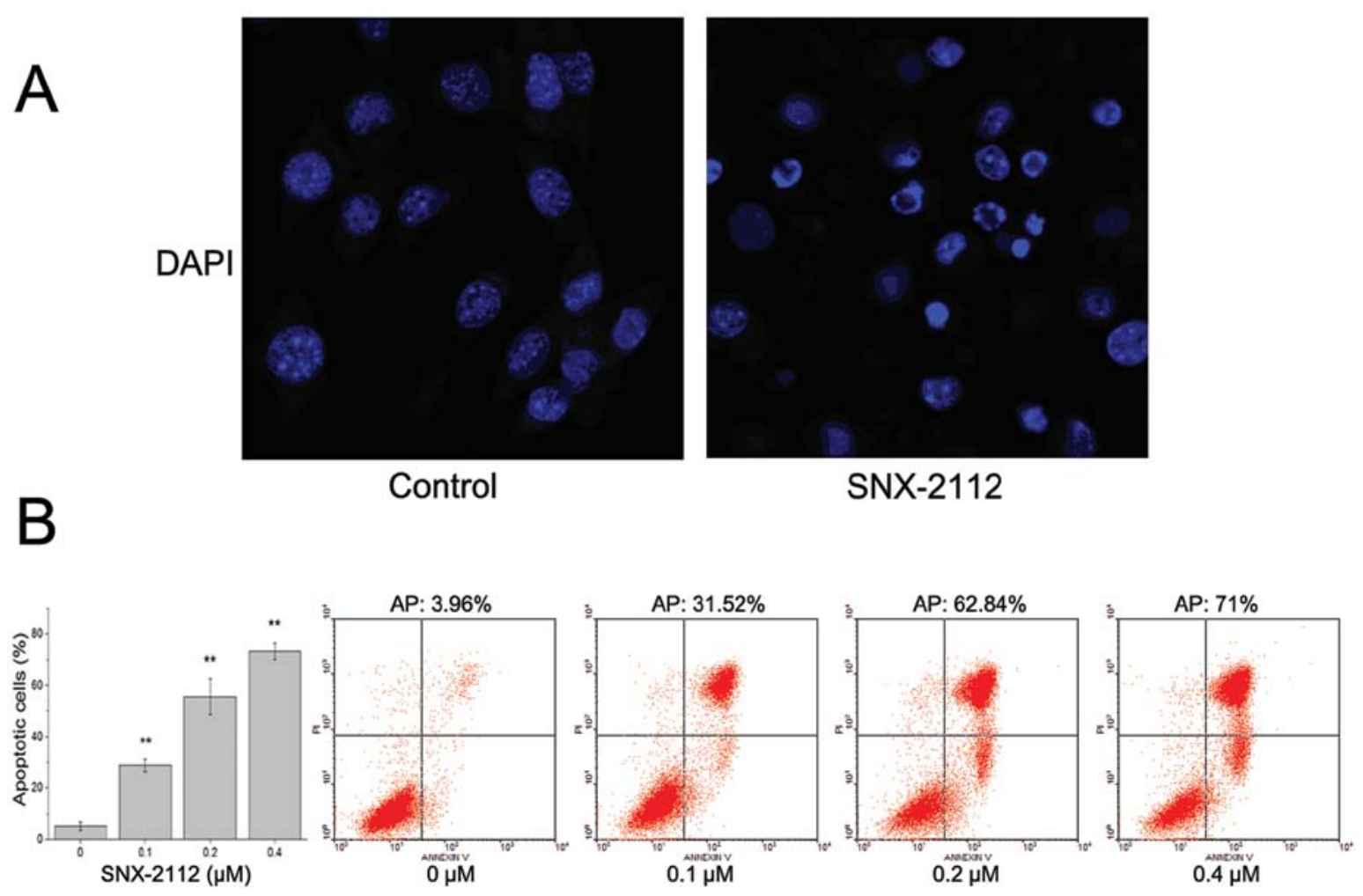

Figure 3. SNX-2112 induces apoptosis in B16 cells. (A) B16 cells were treated with $0.2 \mu \mathrm{M}$ SNX-2112 for $48 \mathrm{~h}$, stained with DAPI and morphological changes were assessed using fluorescent microscopy. (B) Quantification of apoptosis using the Annexin V-FITC/PI dual staining assay in B16 cells treated with the indicated concentrations of SNX-2112 for $48 \mathrm{~h}$. All values are the mean \pm SD of three independent experiments; $\mathrm{P}<0.05$ and ${ }^{* *} \mathrm{P}<0.01$, compared to untreated control cells.

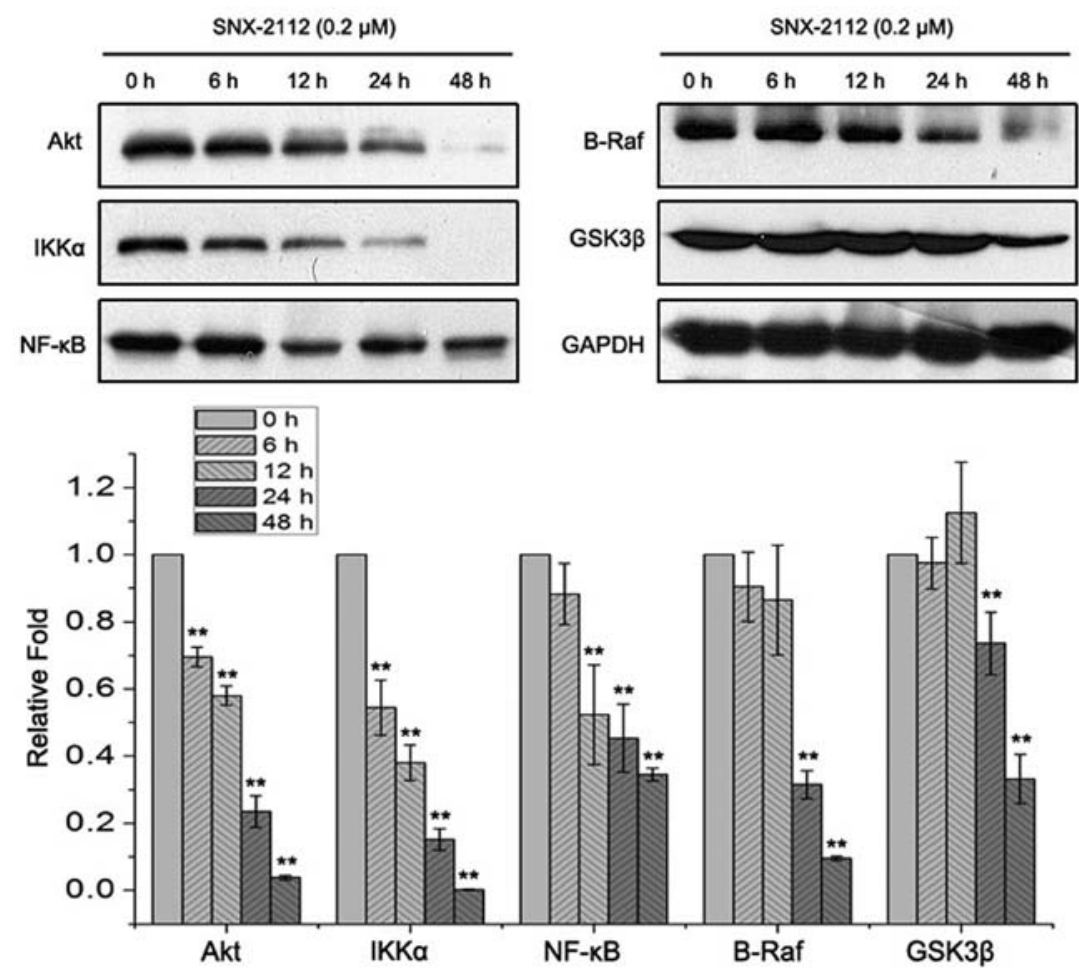

Figure 4. SNX-2112 induces Hsp90 client protein degradation in B16 cells. B16 cells were cultured with $0.2 \mu \mathrm{M}$ SNX-2112 for the indicated times and subjected to Western blot analysis for Hsp90 client proteins. GAPDH was used as a loading control.

SNX-2112 induces the degradation of Hsp90 client proteins. We investigated expression of the Hsp90 client proteins Akt, IKK $\alpha$, $\mathrm{NF}-\kappa \mathrm{B}, \mathrm{B}-\mathrm{Raf}$ and GSK3$\beta$, which are crucial for cell growth, in SNX-2112-treated B16 cells. Western blot analysis indicated that SNX-2112 reduced the expression levels of these proteins in a time-dependent manner (Fig. 4). After treatment with $0.2 \mu \mathrm{M}$ 
A
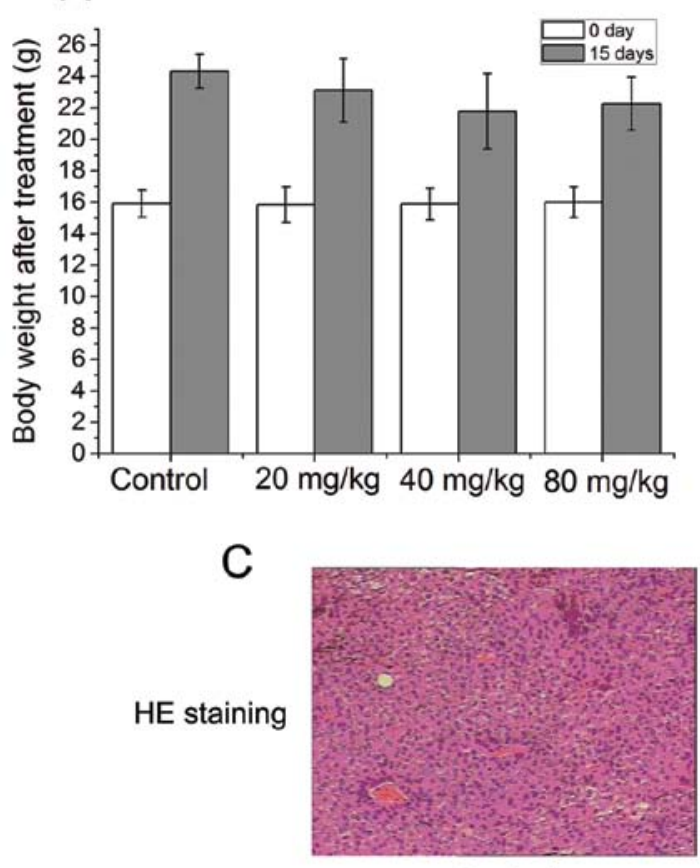

Control
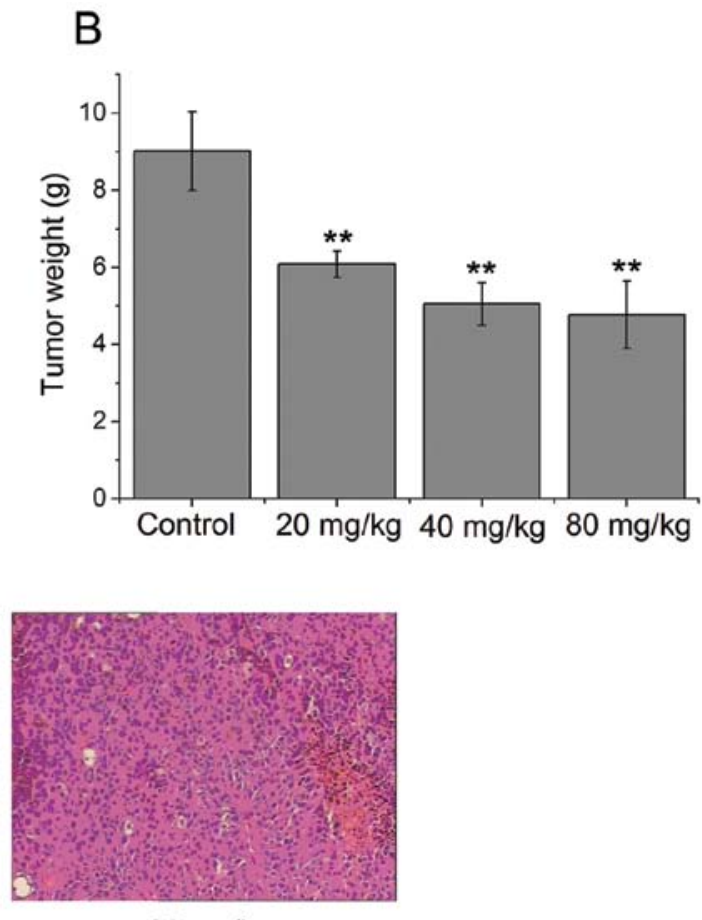

$80 \mathrm{mg} / \mathrm{kg}$

Figure 5. SNX-2112 inhibits in vivo tumor growth. Mice were inoculated with B16 cells and once the tumors were established, the mice were treated with the indicated concentrations of SNX-2112 or DMSO vehicle for 15 days. (A) The influence of SNX-2112 treatment on body weight. (B) The influence of SNX-2112 treatment on tumor weight at 15 days. Values represent mean $\pm \mathrm{SD}, \mathrm{n}=10 ;{ }^{*} \mathrm{P}<0.05$ and ${ }^{* *} \mathrm{P}<0.01$, compared to the control tumors. (C) Representative $\mathrm{H} \& \mathrm{E}$ stained sections of B16 xenograft tissues indicating that administration of SNX-2112 lead to a reduced blood vessel density. Blood vessels are stained light pink/crimson (x200).

SNX-2112 for $48 \mathrm{~h}$, the expression of Akt, IKK $\alpha, \mathrm{NF}-\kappa \mathrm{B}, \mathrm{B}-\mathrm{Raf}$, and GSK $3 \beta$ was significantly decreased to $3.8,0.1,34.5,9.5$ and $33.2 \%$, respectively (compared to control cells, all $\mathrm{P}<0.01$ ). These results suggest that the inhibition of B16 cell growth by SNX-2112 is associated with degradation of the Hsp90 client proteins Akt, IKK $\alpha, \mathrm{NF}-\kappa \mathrm{B}, \mathrm{B}-\mathrm{Raf}$ and GSK3$\beta$.

SNX-2112 inhibits B16 xenograft tumor growth. To further examine the therapeutic effect of SNX-2112 in vivo, we treated C57BL/6 mice bearing B16 tumor xenografts with 20, 40 or $80 \mathrm{mg} / \mathrm{kg}$ SNX-2112 for 15 days, while the control group was treated with physiological saline containing 10\% DMSO. Body weight was measured each day before the administration of SNX-2112. Fig. 5A shows that the body weight of all animals increased over the period of the experiment. At the end of the experiment, tumor weight was measured. As shown in Fig. 5B, the tumor weights of the SNX-2112-treated groups were significantly lower than the vehicle treated control group $(\mathrm{P}<0.01)$.

Furthermore, when the tumor weight was subtracted from the body weight, the 20,40 and $80 \mathrm{mg} / \mathrm{kg}$ SNX-2112 treated groups had an increased body weight $(1,1$ and $1.5 \mathrm{~g}$, respectively), while the control group had a reduced body weight $(1 \mathrm{~g})$. These results suggest that SNX-2112 has a good anti-tumor therapeutic activity in vivo.

As blood vessels are critical for the growth of tumors in vivo, the tumor vessel density was determined in H\&E stained xenograft tumor sections to further analyze the effects of SNX-2112 in vivo. The tumor vessel density of the $80 \mathrm{mg} / \mathrm{kg} \mathrm{SNX}-2112$ group was obviously reduced compared to the control group (Fig. 5C).

\section{Discussion}

The incidence of melanoma is continuously increasing worldwide. Melanoma is one of the most aggressive forms of cancer, and is usually resistant to chemotherapy agents (18). The in vitro experiments of this study demonstrated that SNX-2112, a selective Hsp90 inhibitor, time- and dose-dependently lead to growth inhibition (Fig. 1), accumulation of cells in the G0/G1 phase (Fig. 2) and apoptosis (Fig. 3) in B16 melanoma cells. Additionally, the growth inhibitory ability of SNX-2112 was much more potent than 17-AAG. We also observed that the growth inhibitory effect of SNX-2112 was associated with downregulation of the Hsp90 client proteins Akt, IKK $\alpha, \mathrm{NF}_{-} \kappa \mathrm{B}, \mathrm{B}-\mathrm{Raf}$ and GSK3$\beta$ (Fig. 4). In the in vivo experiments, SNX-2112 exhibited a significant anti-tumor activity in B16 melanoma cell xenografts, without displaying signs of significant toxicity. This study demonstrated that SNX-2112 can significantly inhibit the proliferation and/ or growth of B16 melanoma cells, and has potential beneficial therapeutic effects for the treatment of solid tumors.

The MTT assay indicated that SNX-2112 reduced the viability of B16 melanoma cells in a time- and dose-dependent manner, and exerted more potent effects than the classical Hsp90 inhibitor 17-AAG (Fig. 1). In addition, SNX-2112 reduced cell proliferation in a concentration-dependent manner within the range $0.039-0.625 \mu \mathrm{M}$, but reached a plateau at higher concentrations $(0.625-10 \mu \mathrm{M})$. This may indicate that the anti-tumor mechanisms of SNX-2112 differ from cytotoxic drugs, which do not exhibit limited dose-effect relationships (19). In our previous work, SNX-2112 showed a highly significant anti-proliferative effect on MCF-7 cells (16). 
SNX-2112 significantly increased the percentage of B16 cells in the G0/G1 phase. As the percentage of G0/G1 cells increased, the percentage of $\mathrm{S}$ phase cells decreased and the percentage of G2/M cells slightly changed. These results indicate that SNX-2112 can inhibit B16 cell growth via a mechanism involving G0/G1 arrest. It is possible that the Hsp90 client protein p53 may play a key role in the cell cycle distribution in B16 cells (20). As reported, 17-AAG induced $\mathrm{G}(0 / 1)$ cell cycle arrest and apoptosis in a dose- and time-dependent manner in mantle cell lymphoma cell lines by depleting levels of cyclin D1, Akt, Bid and activating caspase 9 (21). Additional studies are needed to clearly investigate the molecular mechanism by which SNX-2112 leads to arrest of B16 cells in the G0/G1 phase of the cell cycle. To confirm whether SNX-2112-induced cell death occurred via apoptosis, we examined the ability of SNX-2112 to induce the characteristic morphological changes of apoptosis using DAPI staining. Marked morphologic alterations indicative of apoptosis, including nuclear condensation, were observed in cells treated with $0.2 \mu \mathrm{M} \mathrm{SNX}-2112$ for $48 \mathrm{~h}$ (Fig. 3A). To further investigate whether the growth inhibitory effect of SNX-2112 was due to apoptosis, we quantified apoptosis in B16 cells using the Annexin V-FITC/PI assay. The number of early and late apoptotic cells and necrotic cells in B16 cells treated with SNX-2112 was significantly increased (Fig. 3B). These results indicate that the anticancer effects of SNX-2112 in B16 cells may be due to the ability to induce G0/G1 arrest and apoptosis. However, in our previous work, we have found that SNX-2112 induced G2/M cell cycle arrest in A375 (data not shown) and MCF-7 cells (16).

Inhibition of Hsp90 using small molecules results in the rapid degradation of client proteins via the ubiquitin/proteasome pathway, which leads to a significant reduction in the activity of growth-promoting signaling pathways (22). Therefore, in order to determine the mechanism by which SNX-2112 inhibited proliferation and induced G0/G1 arrest and apoptosis, we investigated the effects of SNX-2112 on the protein expression of Akt, IKK $\alpha, N F-\kappa B, B-R a f$ and GSK3 $\beta$, which are related to cell growth $(23,24)$. SNX-2112 potently and time-dependently downregulated the expression of all of the Hsp90 client proteins tested (Fig. 4). These results demonstrated that SNX-2112 mediates the degradation of Hsp90 client proteins and attenuates Akt/GSK3 $\beta$, IKK $\alpha / N F-\kappa B$ and MAPK signaling. Inhibition of these proteins is associated with reduced proliferation of melanoma cells (25-29). Both the Ras/Raf/MEK/Erk (MAPK) and the phosphatidylinositol 3-kinase (PI3K)/AKT signaling pathways are constitutively activated via multiple mechanisms in melanoma $(30,31)$. AKT is a serine threonine kinase downstream of PI3K, which has a large number of downstream targets implicated in survival and cell cycle regulation $(32,33)$. The IKK complex plays a central role in NF- $\kappa \mathrm{B}$ activation and has various biological effects in cancer cells (34). Constitutive activation of $\mathrm{NF}-\kappa \mathrm{B}$ is an emerging hallmark of a wide variety of tumor types, including melanoma (35). Mutated B-Raf is frequently detected in melanoma cells and appears to be a key activator of MEK/Erk signaling; however, Hsp90 inhibitors can induce the degradation of B-Raf (31). The $\alpha$ and $\beta$ forms of GSK3, are critical regulators of apoptosis (36), and GSK3 $\beta$ may play an important role in Hsp90 inhibitor-treated cells (37). GSK3 oppositely regulates the two major apoptotic signaling pathways, the mitochondrial intrinsic apoptotic pathway and the death receptor-mediated extrinsic apoptotic signaling pathway, to induce either anti- or pro-apoptotic actions (38).

In vivo, $\mathrm{SNX}-2112$ significantly inhibited the growth of $\mathrm{B} 16$ melanoma xenograft tumors, demonstrating that SNX-2112 can exert a potent anti-tumor effect. The reduced tumor growth of mice treated with SNX-2112 could be explained, at least in part, by a decreased blood vessel density in the tumor tissues. These results are consistent with a previous report, which showed that the administration of SNX-2112 led to tumor growth inhibition and reduced angiogenesis in multiple myeloma xenografts (13).

In conclusion, this study demonstrated that SNX-2112 can exhibit a potent anticancer activity against B16 melanoma cells in vitro and in vivo. These findings indicated that SNX-2112 is a potent chemotherapeutic agent which can inhibit cell proliferation and induce cell cycle arrest and apoptosis. Our in vitro experiments suggested that SNX-2112 induces the degradation of Hsp90 client proteins, leading to the inhibition of Akt/GSK3 $\beta, \mathrm{IKK} \alpha / \mathrm{NF}-\kappa \mathrm{B}$ and MAPK signaling which inhibits cell growth, and induces apoptosis and cell cycle arrest. Additionally, SNX-2112 significantly inhibited tumor growth and decreased blood vessel density in vivo. The results of this study provided evidence that SNX-2112 has potential for the treatment of melanoma.

\section{Acknowledgements}

This study was supported by grants from the National Natural Science Foundation of China (no. 81001449), and the IndustryAcademia-Research Demostration Base of Guangdong Higher Education Institutes (Namely Innovative Culturing Base of Graduates) (no. 2010B091000013).

\section{References}

1. Bishop SC, Burlison JA and Blagg BS: Hsp90: a novel target for the disruption of multiple signaling cascades. Curr Cancer Drug Targets 7: 369-388, 2007.

2. Chiosis G, Vilenchik M, Kim J and Solit D: Hsp90: the vulnerable chaperone. Drug Discov Today 9: 881-888, 2004.

3. Neckers L: Heat shock protein 90: the cancer chaperone. J Biosci 32: 517-530, 2007.

4. Zuehlke A and Johnson JL: Hsp90 and co-chaperones twist the functions of diverse client proteins. Biopolymers 93: 211-217, 2010.

5. Pearl LH and Prodromou C: Structure and mechanism of the Hsp90 molecular chaperone machinery. Annu Rev Biochem 75: 271-294, 2006.

6. Burrows F, Zhang $\mathrm{H}$ and Kamal A: Hsp90 activation and cell cycle regulation. Cell Cycle 3: 1530-1536, 2004.

7. Zhang $\mathrm{H}$ and Burrows F: Targeting multiple signal transduction pathways through inhibition of Hsp90. J Mol Med 82: 488-499, 2004.

8. Neckers L, Mimnaugh E and Schulte TW: Hsp90 as an anticancer target. Drug Resist Updat 2: 165-172, 1999.

9. Porter JR, Fritz CC and Depew KM: Discovery and development of Hsp90 inhibitors: a promising pathway for cancer therapy. Curr Opin Chem Biol 14: 412-420, 2010.

10. Cysyk RL, Parker RJ, Barchi JJ Jr, Steeg PS, Hartman NR and Strong JM: Reaction of geldanamycin and C17-substituted analogues with glutathione: product identifications and pharmacological implications. Chem Res Toxicol 19: 376-381, 2006.

11. Taldone T, Sun W and Chiosis G: Discovery and development of heat shock protein 90 inhibitors. Bioorg Med Chem 17: 2225-2235, 2009.

12. Powers MV and Workman P: Targeting of multiple signalling pathways by heat shock protein 90 molecular chaperone inhibitors. Endocr Relat Cancer 13 (Suppl. 1): S125-S135, 2006. 
13. Okawa Y, Hideshima T, Steed P, et al: SNX-2112, a selective Hsp90 inhibitor, potently inhibits tumor cell growth, angiogenesis, and osteoclastogenesis in multiple myeloma and other hematologic tumors by abrogating signaling via Akt and ERK. Blood 113: 846-855, 2009.

14. Bachleitner-Hofmann T, Sun MY, Chen CT, et al: Antitumor activity of SNX-2112, a synthetic heat shock protein-90 inhibitor, in MET-amplified tumor cells with or without resistance to selective MET inhibition. Clin Cancer Res 17: 122-133, 2011.

15. Jin L, Xiao CL, Lu CH, et al: Transcriptomic and proteomic approach to studying SNX-2112-induced K562 cells apoptosis and anti-leukemia activity in K562-NOD/SCID mice. FEBS Lett 583: 1859-1866, 2009

16. Wang SX, Ju HQ, Liu KS, et al: SNX-2112, a novel Hsp90 inhibitor, induces G2/M cell cycle arrest and apoptosis in MCF-7 cells. Biosci Biotechnol Biochem 75: 1540-1545, 2011.

17. Barta TE, Veal JM, Rice JW, et al: Discovery of benzamide tetrahydro-4H-carbazol-4-ones as novel small molecule inhibitors of Hsp90. Bioorg Med Chem Lett 18: 3517-3521, 2008.

18. Pinon A, Limami Y, Micallef L, et al: A novel form of melanoma apoptosis resistance: melanogenesis up-regulation in apoptotic B16-F0 cells delays ursolic acid-triggered cell death. Exp Cell Res 317: 1669-1676, 2011.

19. Untch M, von Koch F, Kahlert S and Konecny G: Overview of epirubicin-based adjuvant therapy in breast cancer. Clin Breast Cancer 1 (Suppl 1): S41-S45, 2000.

20. Rakitina TV, Vasilevskaya IA and O'Dwyer PJ: Inhibition of G1/S transition potentiates oxaliplatin-induced cell death in colon cancer cell lines. Biochem Pharmacol 73: 1715-1726, 2007.

21. Georgakis GV, Li Y and Younes A: The heat shock protein 90 inhibitor 17-AAG induces cell cycle arrest and apoptosis in mantle cell lymphoma cell lines by depleting cyclin D1, Akt, Bid and activating caspase 9. Br J Haematol 135: 68-71, 2006.

22. Theodoraki MA and Caplan AJ: Quality control and fate determination of Hsp90 client proteins. Biochim Biophys Acta 1823 683-688 2011.

23. Massey AJ, Schoepfer J, Brough PA, et al: Preclinical antitumor activity of the orally available heat shock protein 90 inhibitor NVP-BEP800. Mol Cancer Ther 9: 906-919, 2010.

24. Banerji U: Heat shock protein 90 as a drug target: some like it hot. Clin Cancer Res 15: 9-14, 2009.

25. Ye Y, Wang H, Chu JH, et al: Atractylenolide II induces G1 cellcycle arrest and apoptosis in B16 melanoma cells. J Ethnopharmacol 136: 279-282, 2011.

26. Samadi AK, Zhang X, Mukerji R, Donnelly AC, Blagg BS and Cohen MS: A novel C-terminal HSP90 inhibitor KU135 induces apoptosis and cell cycle arrest in melanoma cells. Cancer Lett 312: 158-167, 2011.
27. Sala E, Mologni L, Truffa S, Gaetano C, Bollag GE and Gambacorti-Passerini C: BRAF silencing by short hairpin RNA or chemical blockade by PLX4032 leads to different responses in melanoma and thyroid carcinoma cells. Mol Cancer Res 6: 751-759, 2008.

28. Panka DJ, Cho DC, Atkins MB and Mier JW: GSK-3beta inhibition enhances sorafenib-induced apoptosis in melanoma cell lines. J Biol Chem 283: 726-732, 2008.

29. Papp T, Niemetz A, Dosdahl N, Kumar K and Schiffmann D: Mutational analysis of Chk1, Chk2, Apaf1 and Rb1 in human malignant melanoma cell lines. Oncol Rep 17: 135-140, 2007.

30. Russo AE, Torrisi E, Bevelacqua Y, et al: Melanoma: molecular pathogenesis and emerging target therapies (review). Int J Oncol 34: 1481-1489, 2009.

31. Mehta PP, Kung PP, Yamazaki S, et al: A novel class of specific Hsp90 small molecule inhibitors demonstrate in vitro and in vivo anti-tumor activity in human melanoma cells. Cancer Lett 300: 30-39, 2011.

32. Vivanco I and Sawyers CL: The phosphatidylinositol 3-kinase AKT pathway in human cancer. Nat Rev Cancer 2: 489-501, 2002.

33. Jia W, Yu C, Rahmani M, et al: Synergistic antileukemic interactions between 17-AAG and UCN-01 involve interruption of RAF/MEK- and AKT-related pathways. Blood 102: 1824-1832, 2003.

34. Park K, Choi K, Kim H, et al: Isoflavone-deprived soy peptide suppresses mammary tumorigenesis by inducing apoptosis. Exp Mol Med 41: 371-381, 2009.

35. Prasad S, Ravindran J and Aggarwal BB: NF-kappaB and cancer: how intimate is this relationship. Mol Cell Biochem 336: 25-37, 2010.

36. Lochhead PA, Kinstrie R, Sibbet G, Rawjee T, Morrice N and Cleghon V: A chaperone-dependent GSK3beta transitional intermediate mediates activation-loop autophosphorylation. Mol Cell 24: 627-633, 2006

37. Kurashina R, Ohyashiki JH, Kobayashi C, et al: Anti-proliferative activity of heat shock protein (Hsp) 90 inhibitors via betacatenin/TCF7L2 pathway in adult $\mathrm{T}$ cell leukemia cells. Cancer Lett 284: 62-70, 2009.

38. Beurel E and Jope RS: The paradoxical pro- and anti-apoptotic actions of GSK3 in the intrinsic and extrinsic apoptosis signaling pathways. Prog Neurobiol 79: 173-189, 2006. 